\title{
Performance Improvement of GaN-Based Flip-Chip White Light-Emitting Diodes with Diffused Nanorod Reflector and with ZnO Nanorod Antireflection Layer
}

\author{
Hsin-Ying Lee, ${ }^{1}$ Yu-Chang Lin, ${ }^{1}$ Yu-Ting Su, ${ }^{1}$ Chia-Hsin Chao, ${ }^{2}$ and Véronique Bardinal ${ }^{3,4}$ \\ ${ }^{1}$ Department of Photonics, Advanced Optoelectronic Technology Center, National Cheng Kung University, Tainan 701, Taiwan \\ ${ }^{2}$ Electronics and Optoelectronics Research Laboratories, Industrial Technology Research Institute, Hsinchu 300, Taiwan \\ ${ }^{3}$ CNRS, LAAS, 7 avenue du Colonel Roche, 31077 Toulouse, France \\ ${ }^{4}$ University of Toulouse, UPS, INSA, INP, ISAE, LAAS, 31077 Toulouse, France
}

Correspondence should be addressed to Hsin-Ying Lee; hylee@ee.ncku.edu.tw

Received 23 November 2013; Accepted 31 December 2013; Published 12 February 2014

Academic Editor: Sheng-Po Chang

Copyright (C) 2014 Hsin-Ying Lee et al. This is an open access article distributed under the Creative Commons Attribution License, which permits unrestricted use, distribution, and reproduction in any medium, provided the original work is properly cited.

\begin{abstract}
The GaN-based flip-chip white light-emitting diodes (FCWLEDs) with diffused $\mathrm{ZnO}$ nanorod reflector and with $\mathrm{ZnO}$ nanorod antireflection layer were fabricated. The $\mathrm{ZnO}$ nanorod array grown using an aqueous solution method was combined with $\mathrm{Al}$ metal to form the diffused $\mathrm{ZnO}$ nanorod reflector. It could avoid the blue light emitted out from the Mg-doped GaN layer of the FCWLEDs, which caused more blue light emitted out from the sapphire substrate to pump the phosphor. Moreover, the ZnO nanorod array was utilized as the antireflection layer of the FCWLEDs to reduce the total reflection loss. The light output power and the phosphor conversion efficiency of the FCWLEDs with diffused nanorod reflector and $250 \mathrm{~nm}$ long $\mathrm{ZnO}$ nanorod antireflection layer were improved from $21.15 \mathrm{~mW}$ to $23.90 \mathrm{~mW}$ and from $77.6 \%$ to $80.1 \%$ in comparison with the FCWLEDs with diffused nanorod reflector and without $\mathrm{ZnO}$ nanorod antireflection layer, respectively.
\end{abstract}

\section{Introduction}

Recently, people have paid more and more attention to the problems of energy shortage and environment problems. Many research teams actively investigated how to improve energy saving and how to produce renewable energy. The white light-emitting diodes (WLEDs) are expected to be the promising green lighting sources and have been widely used in solid-state lighting and taken as the next generation lighting sources to replace the compact fluorescent lamp (CFL) and incandescent light. The WLEDs exhibit many superior advantages such as the long lifetime, high luminous intensity, energy saving, fast response, low heat dissipation, and high reliability. In general, there are three approaches that can be used to fabricate WLEDs: (1) using the blue lightemitting diodes (LEDs) to excite the yellow phosphor [1,2], (2) using an ultraviolet (UV) LEDs to excite red, green, and blue phosphors $[3,4]$, and (3) mixing three primary colors of red, green, and blue LEDs [5]. The commercial WLEDs were commonly integrated by the GaN-based blue LEDs with yellow phosphor $\left(\mathrm{Y}_{3} \mathrm{Al}_{5} \mathrm{O}_{12}: \mathrm{Ce}_{3}{ }^{+}\right.$or $\left.\mathrm{YAG}: \mathrm{Ce}_{3}{ }^{+}\right)$layer. To augment the application of WLEDs, the development of high performance WLEDs is immediately needed. Since the properties of the GaN-based blue LEDs seriously affect the performances of WLEDs, how to improve the internal quantum efficiency and external quantum efficiency of the blue LEDs is a primary issue. In view of the significant progress of GaN-based epitaxial technology, the internal quantum efficiency of the GaN-based blue LEDs achieved the theoretical limit of $90 \%$. However, the large difference of refractive index between the GaN-based semiconductor $\left(n_{\mathrm{GaN}}=2.4\right)$ and the air $\left(n_{\mathrm{air}}=1\right)$ led to the increase of total internal reflection and the Fresnel loss. Generally, several methods, such as die shape [6,7], surface roughness $[8,9]$, photonic crystal $[10,11]$, reflector $[12,13]$, and antireflection coating layer [14], have been reported previously to overcome the undesired total internal reflection and Fresnel loss. Among these methods, the reflector exhibits 


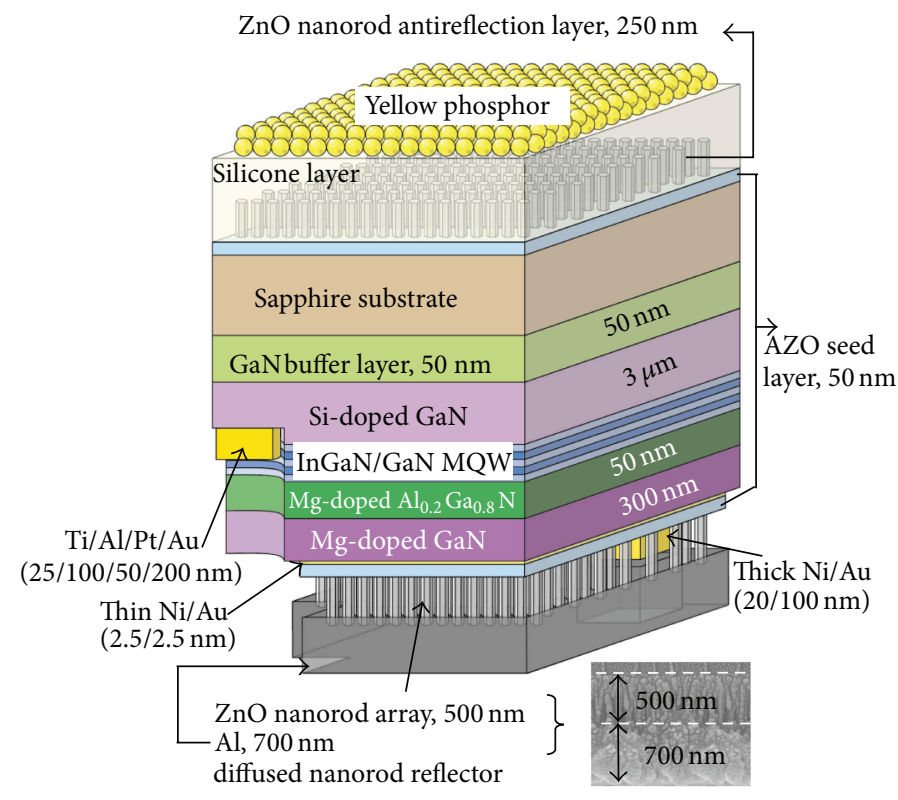

Figure 1: The schematic configuration of the GaN-based FCWLEDs with diffused nanorod reflector and with ZnO nanorod antireflection layer. The inset figure shows the morphology of diffused nanorod reflector.

several advantages including simple fabrication, low cost, and outstanding light extraction improvement of LEDs. In this work, to improve the light extraction efficiency of WLEDs, the designed diffused nanorod reflector constructed with the $700 \mathrm{~nm}$ thick $\mathrm{Al}$ metal and $\mathrm{ZnO}$ nanorod array with optimal rod length of $500 \mathrm{~nm}$ was used in the flipchip white light-emitting diodes (FCWLEDs). The detail, investigation of diffused nanorod reflector was shown in previous published paper [15]. The diffused nanorod reflector could effectively increase the reflection angle and enhance the light escaping probability from the semiconductor compared with the traditional flat reflector. Furthermore, to further improve the light extraction from the light-emitted side of the FCWLEDs, the $\mathrm{ZnO}$ nanorod arrays were also used as the antireflection layer. Finally, the yellow phosphor layer was coated on the $\mathrm{ZnO}$ nanorod antireflection layer by using the remote phosphor coating technique which possessed the uniformity and high color conversion efficiency.

\section{Experiment Procedure}

Figure 1 shows the schematic configuration of the GaNbased FCWLEDs with diffused nanorod reflector and with $\mathrm{ZnO}$ nanorod antireflection layer. A metal organic chemical vapor deposition (MOCVD) system was used to grow the epitaxial layers of the GaN-based blue LEDs. A $2.8 \mu \mathrm{m}$ thick GaN buffer layer, a $4 \mu \mathrm{m}$ thick Si-doped GaN layer $\left(n=3 \times 10^{17} \mathrm{~cm}^{-3}\right)$, an undoped InGaN/GaN multiple quantum well (MQW) active layer, a $33 \mathrm{~nm}$ thick Mg-doped $\mathrm{Al}_{0.2} \mathrm{Ga}_{0.8} \mathrm{~N}$ layer $\left(p=1 \times 10^{17} \mathrm{~cm}^{-3}\right)$, and a $150 \mathrm{~nm}$ thick Mg-doped GaN layer $\left(p=3 \times 10^{17} \mathrm{~cm}^{-3}\right)$ were sequentially grown on the c-plane sapphire substrates. The InGaN/GaN MQW active layer was consisted of twelve pairs of $3 \mathrm{~nm}$ thick $\operatorname{In}_{0.2} \mathrm{Ga}_{0.8} \mathrm{~N}$ well layer and $12.7 \mathrm{~nm}$ thick GaN barrier layer. The fabrication processes of the conventional GaNbased LEDs are as follows. The epitaxial layer with mesa $\left(300 \times 300 \mu \mathrm{m}^{2}\right)$ pattern protected by a $300 \mathrm{~nm}$ thick $\mathrm{Ni}$ metal mask was etched down to the Si-doped GaN layer by a reactive ion etching (RIE) system. After the mesa etching, the remaining Ni metal mask was removed using aqua regia. The n-electrode $\mathrm{Ti} / \mathrm{Al} / \mathrm{Ti} / \mathrm{Au}(25 / 100 / 50 / 150 \mathrm{~nm})$ was deposited using an electron-beam evaporator. Moreover, the n-electron was treated by a rapid thermal annealing (RTA) system with $850^{\circ} \mathrm{C}$ for $2 \mathrm{~min}$ in a pure $\mathrm{N}_{2}$ ambient for obtaining the good ohmic contact performance [16]. Thin Ni/Au $(2.5 / 2.5 \mathrm{~nm})$ and thick Ni/Au $(20 / 100 \mathrm{~nm})$ metal contacts were deposited on $\mathrm{Mg}$-doped GaN layer as the current spreading layer (CSL) and the p-electrode, respectively. Prior to thin $\mathrm{Ni} / \mathrm{Au}$ metal deposition, a surface sulfurization treatment was performed to improve the contact performance between the thin $\mathrm{Ni} / \mathrm{Au}$ metals and the Mg-doped GaN mesa region [17]. The ptype ohmic contact formation was carried out in an air ambient at $500^{\circ} \mathrm{C}$ for $10 \mathrm{~min}$ by a RTA system. When the conventional GaN-based LEDs were fabricated, and then the diffused nanorod reflector was sequentially fabricated. A $50 \mathrm{~nm}$ thick Al-doped $\mathrm{ZnO}$ (AZO) seed layer was deposited on the $\mathrm{Ni} / \mathrm{Au}$ current spreading layer using a magnetron radio frequency sputtering system. A $500 \mathrm{~nm}$ long $\mathrm{ZnO}$ nanorod array was grown on the AZO seed layer using an aqueous solution method at $90^{\circ} \mathrm{C}$. The chemical solution was mixed by $0.025 \mathrm{M}$ zinc nitrate hexahydrate $\left(\mathrm{Zn}\left(\mathrm{NO}_{3}\right)_{2}\right.$ $\left.6 \mathrm{H}_{2} \mathrm{O}\right)$ and $0.025 \mathrm{M}$ hexamethylenetetramine $\left(\mathrm{C}_{6} \mathrm{H}_{12} \mathrm{~N}_{4}\right)$. A $700 \mathrm{~nm}$ thick Al metal was then deposited on the top of the $\mathrm{ZnO}$ nanorod array using an electron-beam evaporator. The morphology of diffused nanorod reflector was carried out using scanning electron microscope (SEM) and is shown in the inset of Figure 1. Then a $50 \mathrm{~nm}$ thick AZO seed layer and 


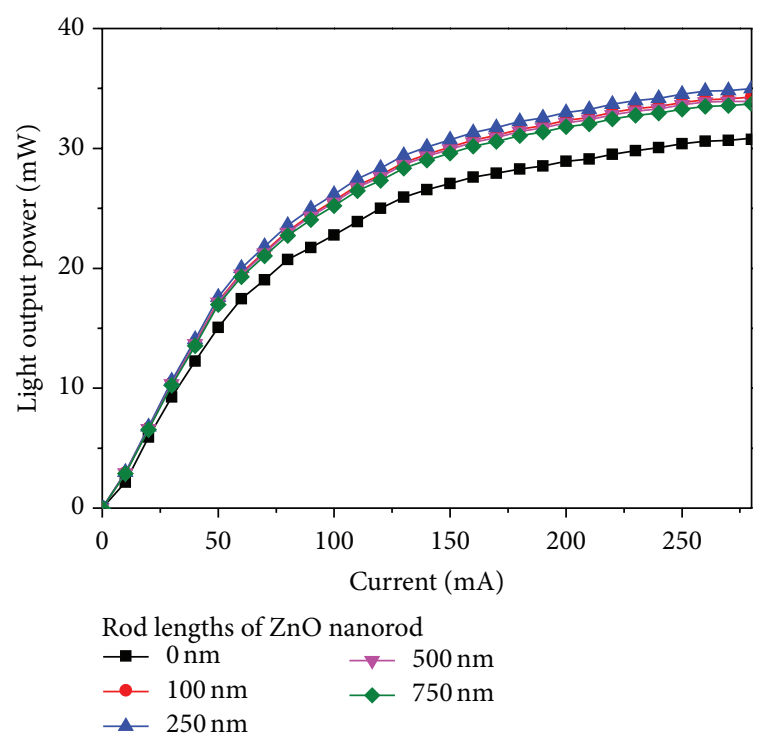

FIGURE 2: The light output power-current curves of the GaN-based FCLEDs with diffused nanorod reflector and with $\mathrm{ZnO}$ nanorod antireflection layers of various rod lengths.

$\mathrm{ZnO}$ nanorod arrays were sequentially deposited on the sapphire surface of the GaN-based FCLEDs with diffuse nanorod reflector. To find the optimal rod length of the $\mathrm{ZnO}$ nanorod in the array as the antireflection layer, the $\mathrm{ZnO}$ nanorods with various rod lengths of $0,100,250,500$, and $700 \mathrm{~nm}$ were grown. Finally, the remote phosphor coating technique was used to form the GaN-based FCWLEDs. A silicone layer was spread on the $250 \mathrm{~nm}$ long $\mathrm{ZnO}$ nanorod antireflection layer and a yellow phosphor layer was covered on the silicone layer to complete the fabrication process of the FCWLEDs with diffused nanorod reflector and with $\mathrm{ZnO}$ nanorod antireflection layer. The FCWLEDs with diffused nanorod reflector and $250 \mathrm{~nm}$ long $\mathrm{ZnO}$ nanorod antireflection layer were named FCWLED A, hereafter. The FCWLEDs with diffused nanorod reflector and without $250 \mathrm{~nm}$ long $\mathrm{ZnO}$ nanorod antireflection layer (named FCWLED B, hereafter) were also fabricated for comparison.

\section{Result and Discussion}

To find the optimal rod length of the $\mathrm{ZnO}$ nanorod in the antireflection layer, the performances of the GaN-based FCLEDs with diffused nanorod reflector and with 0, 100, 250, 500 , and $750 \mathrm{~nm}$ long $\mathrm{ZnO}$ nanorod arrays were firstly investigated. Figure 2 shows the light output power-current ( $L$ I) curves of the GaN-based FCLEDs with diffused nanorod reflector and with $\mathrm{ZnO}$ nanorod arrays of various rod lengths measured using an integrating sphere. As shown in Figure 2, the light output power of the FCLEDs with diffused nanorod reflector and with $250 \mathrm{~nm}$ long $\mathrm{ZnO}$ nanorod array was improved from $30.85 \mathrm{~mW}$ to $34.99 \mathrm{~mW}$, compared with the FCLEDs with diffused nanorod reflector and without $\mathrm{ZnO}$ nanorod (i.e., $0 \mathrm{~nm}$ long $\mathrm{ZnO}$ nanorod) antireflection layer at an injection current of $280 \mathrm{~mA}$. However, when the rod

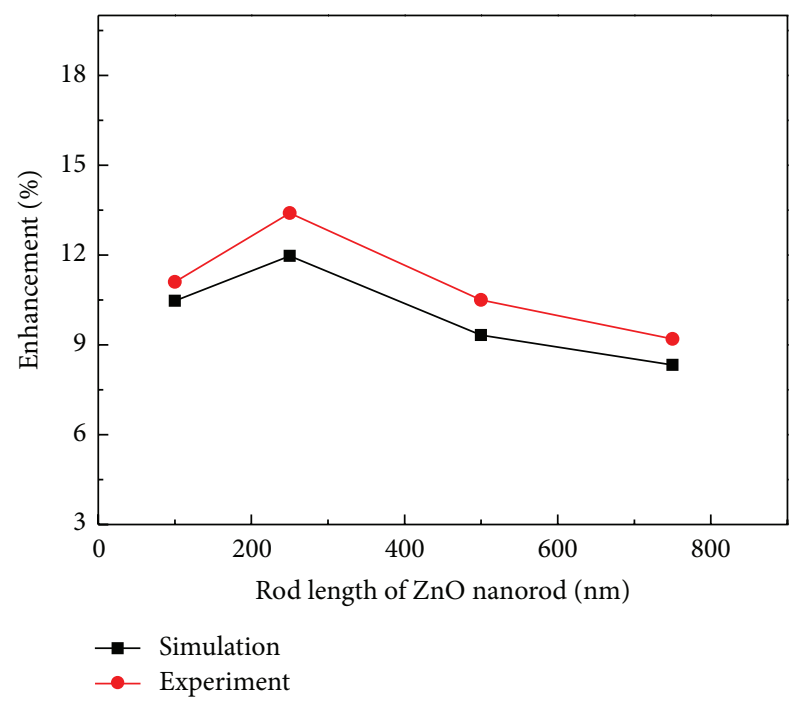

FIGURE 3: The simulating results and experimental results of the enhancement in the illumination efficiency and light output power for the resulting FCLEDs and FCWLEDs with $\mathrm{ZnO}$ nanorod antireflection layers of various rod lengths, in comparison with the resulting FCLEDs and FCWLEDs without $\mathrm{ZnO}$ nanorod antireflection layer, respectively.

length of the $\mathrm{ZnO}$ nanorod array was longer than $250 \mathrm{~nm}$, the light output power decreased owing to the absorption of the $\mathrm{ZnO}$ nanorod array. To confirm the optimal rod length of the $\mathrm{ZnO}$ nanorod antireflection layer on the output side of the FCLEDs with diffused nanorod reflector, the standard optical software TracePro was also used to simulate the light propagated within the $\mathrm{ZnO}$ nanorod arrays of various rod lengths. Figure 3 shows the simulating results of an enhancement in the illumination efficiency for the FCLEDs with diffused nanorod reflector and with $\mathrm{ZnO}$ nanorod antireflection layer of various rod lengths, in comparison with the FCLEDs with diffused $\mathrm{ZnO}$ nanorod reflector and without $\mathrm{ZnO}$ nanorod antireflection layer. The illumination efficiency of the FCLEDs with diffused nanorod reflector and with 100, 250, 500, and $750 \mathrm{~nm}$ long $\mathrm{ZnO}$ nanorod antireflection layer showed an increase of $10.47 \%, 11.97 \%, 9.32 \%$, and $8.33 \%$, respectively. The experimental results of the enhanced proportion of the light output power for the resulted FCLEDs are also shown in Figure 3. The experimental results and the simulation results the similar tendency. In addition, the optimal effective refractive index of the antireflection layer can be determined by the formula of $\left(n_{\mathrm{air}} \times n_{\mathrm{GaN}}\right)^{1 / 2}$, where $n_{\text {air }}$ of 1.00 and $n_{\mathrm{GaN}}$ of 2.40 were the refractive indexes of air and $n-G a N$, respectively. The solution of the optimal effective refractive index of the antireflection layer was 1.55. In this work, the effective refractive index of the $250 \mathrm{~nm}$ long $\mathrm{ZnO}$ nanorod antireflection layer was measured by an ellipsometer and the value was about 1.57 which was similar to the optimal effective refractive index of the antireflection layer. Therefore, the rod length of $250 \mathrm{~nm}$ in the $\mathrm{ZnO}$ nanorod antireflection layer was the optimal length for the FCLEDs.

Figure 4 shows the electroluminescence (EL) spectra of the FCWLEDs with diffused nanorod reflector and with 


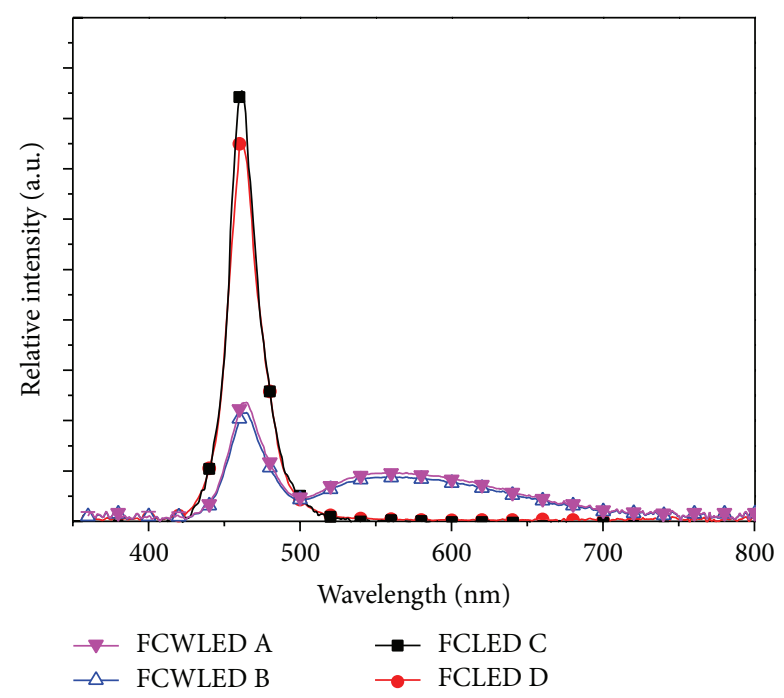

FIGURE 4: The electroluminescence spectra of the resulting FCWLEDs and FCLEDs with and without $250 \mathrm{~nm}$ long ZnO nanorod antireflection layer at an injection current of $20 \mathrm{~mA}$.

and without $250 \mathrm{~nm}$ long $\mathrm{ZnO}$ nanorod antireflection layer (FCWLED A and FCWLED B) at an injection current of $20 \mathrm{~mA}$. The EL spectra of the blue FCLEDs with diffused nanorod reflector and with $250 \mathrm{~nm}$ long $\mathrm{ZnO}$ nanorod antireflection layer (named FCLED C, hereafter) and the blue FCLEDs with diffused nanorod reflector and without $250 \mathrm{~nm}$ long $\mathrm{ZnO}$ nanorod antireflection layer (named FCLED D, hereafter) are also shown in Figure 4. As shown in Figure 4, the light-emission intensity of FCWLED A was larger than that of FCWLED B at the wavelength range from $400 \mathrm{~nm}$ to $700 \mathrm{~nm}$. The light emission intensity of FCLED C and FCLED D had the same situation. The improvement of the light-emission intensity was attributed to the fact that the $250 \mathrm{~nm}$ long $\mathrm{ZnO}$ nanorod antireflection layer could effectively reduce the total reflection loss. The phosphor conversion efficiency $\eta$ of the FCWLEDs was defined as

$$
\eta=\frac{P_{\text {phosphor }}}{P_{p}-P_{\text {phosphor }}},
$$

where $P_{p}$ is the optical power emitted from the blue FCLEDs without phosphor layer and $P_{\text {phosphor }}$ is the optical power converted from the phosphor layer. Compared with the FCWLED B, the phosphor conversion efficiency of FCWLED A operated at an injection current of $20 \mathrm{~mA}$ was improved from $77.6 \%$ to $80.1 \%$. The improvement was attributed to that the $\mathrm{ZnO}$ nanorod antireflection layer could reduce the light total reflection at the sapphire surface, which could guide more blue light to pump the phosphor layer. Generally, the phosphor conversion efficiency was varied by the injection current of the LEDs. Consequently, the EL spectra of the FCLED C and FCWLED A at various injection currents were measured and are shown in Figures 5(a) and 5(b), respectively. Figure 6 shows the phosphor conversion efficiency of FCWLED A at various injection currents which estimated by (1). The phosphor conversion efficiency of FCWLED A was enhanced with an increase of the injection current; a maximum value of $92.5 \%$ was obtained as the FCWLED A operated at a current of $80 \mathrm{~mA}$. This phenomenon was attributed to that the phosphor conversion efficiency reached saturation at an injection current of $80 \mathrm{~mA}$. Therefore, when the injection current was more than $80 \mathrm{~mA}$, the phosphor conversion efficiency decreased owing to the excess blue light directly emitted out the FCWLEDs or the excess photons multi scattered with the phosphor and were absorbed inside the FCWLEDs. The $L-I$ curves of FCWLED A and FCWLED $\mathrm{B}$ were also measured using an integrating sphere system. The light output power of FCWLED A and FCWLED B was $23.90 \mathrm{~mW}$ and $21.15 \mathrm{~mW}$, respectively, at an injection current of $280 \mathrm{~mA}$.

Figure 7 shows the chromaticity diagram of FCWLED A and FCWLED B at an injection current of $80 \mathrm{~mA}$. As shown in Figure 7, the chromaticity coordinate of the emission of the corresponding LEDs exhibited the same coordinates of 0.335 and 0.333 , which demonstrated that the emitted light was a white light.

\section{Conclusions}

The light output power and phosphor conversion efficiency of the FCWLEDs were successfully improved by using the diffused nanorod reflector and the $\mathrm{ZnO}$ nanorod antireflection layer. The diffused nanorod reflector constructed by the $500 \mathrm{~nm}$ long $\mathrm{ZnO}$ nanorod arrays and the high reflective $\mathrm{Al}$ metal could effectively enhance the probability of light reflectivity from the bottom of the FCWLEDs. Moreover, according to the experimental results and the simulation results, the optimal $250 \mathrm{~nm}$ long $\mathrm{ZnO}$ nanorods grown on the output side of the LEDs as the antireflection layer could guide more blue light and could excite more phosphor to enhance the phosphor conversion efficiency. The light output power of the FCWLEDs with diffused nanorod reflector and with $\mathrm{ZnO}$ nanorod antireflection layer was enhanced 13.0\% 


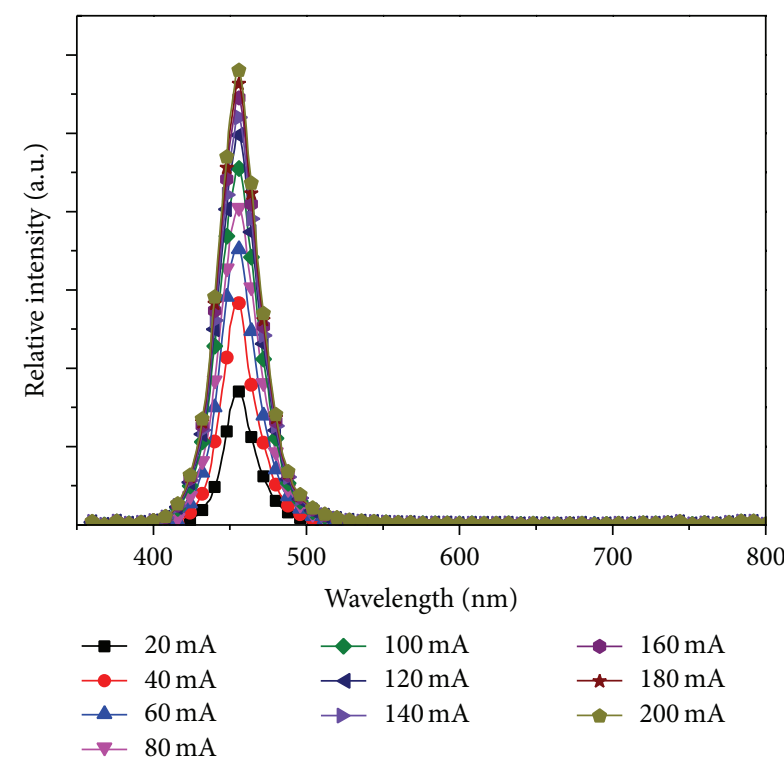

(a)

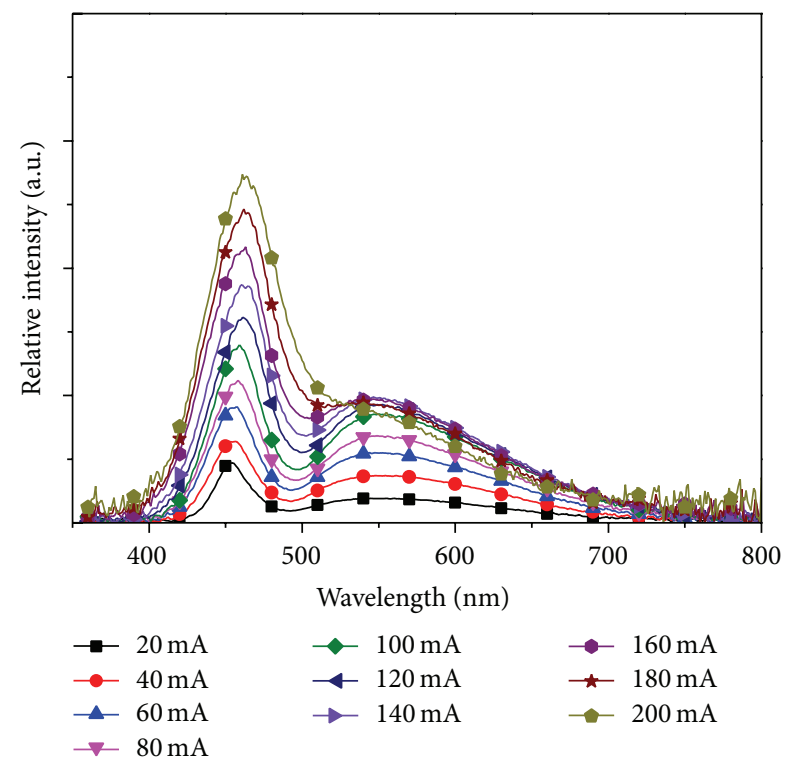

(b)

FIgURE 5: The electroluminescence spectra of (a) FCLED C and (b) FCWLED A at various injection currents.

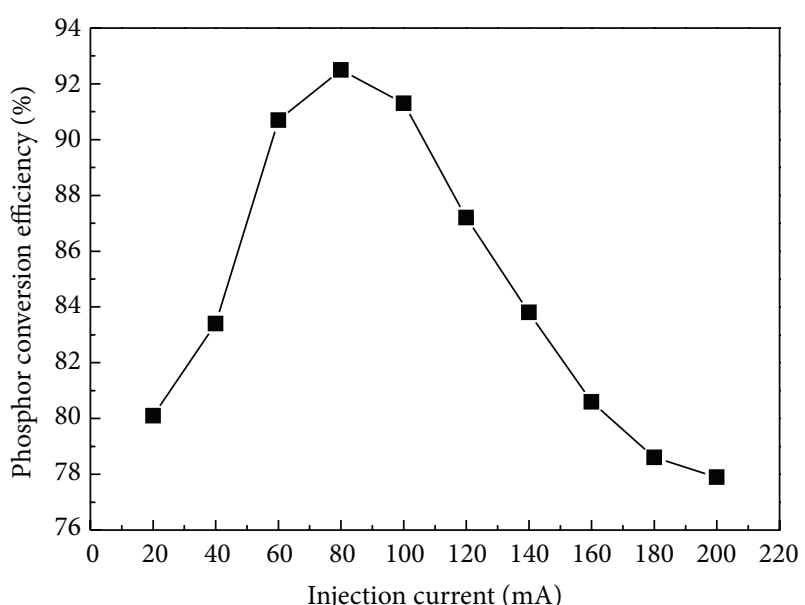

FIGURE 6: The phosphor conversion efficiency of FCWLED A at various injection currents.

in comparison with the FCWLEDs with diffused nanorod reflector and without with $\mathrm{ZnO}$ nanorod antireflection layer at injection current of $280 \mathrm{~mA}$. The phosphor conversion efficiency was also improved by $2.5 \%$.

\section{Conflict of Interests}

The authors declare that there is no conflict of interests regarding the publication of this paper.

\section{Acknowledgments}

This work was supported by the Industrial Technology Research Institute, Bureau of Energy, Ministry of Economic

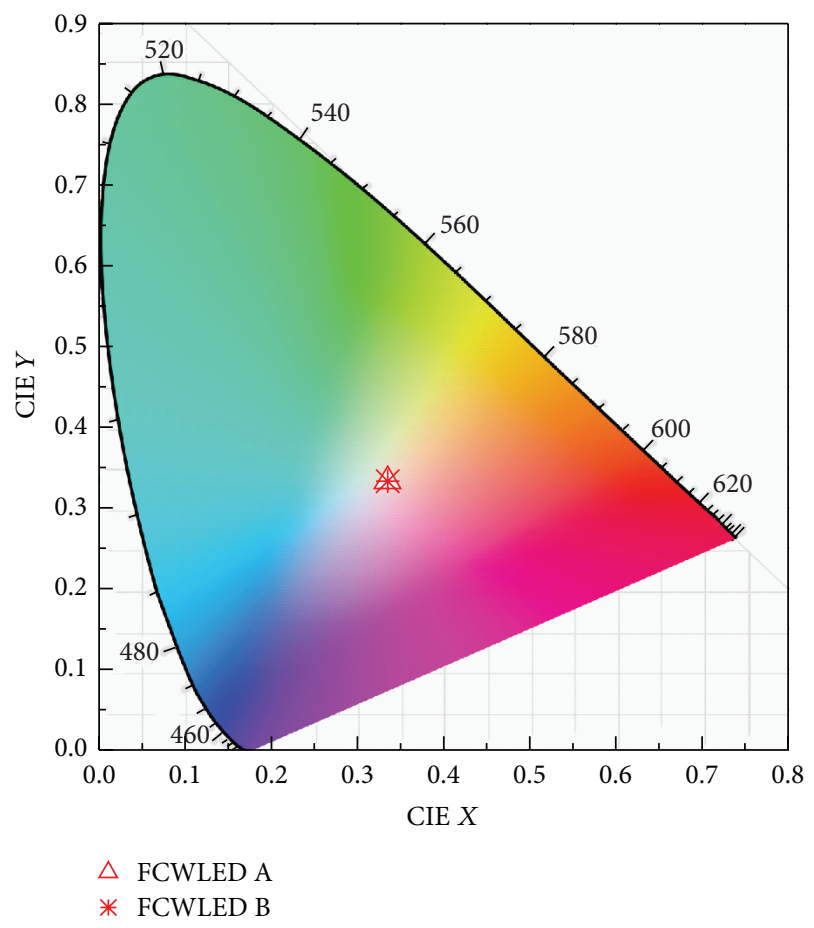

FIGURE 7: The chromaticity diagram of FCWLED A and FCWLED B.

Affairs of Taiwan, Contract no. 102-E0605, the National Sciences Council of Taiwan under Grant NSC-101-2923-E-006004-MY2, and the Advanced Optoelectronic Technology Center, National Cheng Kung University, Taiwan. 


\section{References}

[1] H. Rao, W. Wang, X. L. Wan et al., "An improved slurry method of self-adaptive phosphor coating for white pc-LED packaging," Journal of Display Technology, vol. 9, no. 6, pp. 453-458, 2013.

[2] C. T. Lee and T. J. Wu, "Light distribution and light extraction improvement mechanisms of remote GaN-based white lightemitting-diodes using $\mathrm{ZnO}$ nanorod array," Journal of Luminescence, vol. 137, no. 5, pp. 143-147, 2013.

[3] Z. Y. Mao, Y. C. Zhu, L. Gan et al., "Tricolor emission $\mathrm{Ca}_{3} \mathrm{Si}_{2} \mathrm{O}_{7}$ : Ln $(\mathrm{Ln}=\mathrm{Ce}, \mathrm{Tb}, \mathrm{Eu})$ phosphors for near-UV white lightemitting-diode," Journal of Luminescence, vol. 134, no. 2, pp. 148-153, 2013.

[4] S. H. Park, K. H. Lee, S. Unithrattil, H. S. Yoon, H. G. Jang, and W. B. Im, "Melilite-structure $\mathrm{CaYAl}_{3} \mathrm{O}_{7}: \mathrm{Eu}^{3+}$ phosphor: structural and optical characteristics for near-UV LED based white light," The Journal of Physical Chemistry, vol. 116, no. 51, pp. 26850-26856, 2012.

[5] S. Muthu, F. J. P. Schuurmans, and M. D. Pashley, "Red, green, and blue LEDs for white light illumination," IEEE Journal on Selected Topics in Quantum Electronics, vol. 8, no. 2, pp. 333-338, 2002.

[6] D. S. Kuo, S. J. Chang, T. K. Ko, C. F. Shen, S. J. Hon, and S. C. Hung, "Nitride-based LEDs with phosphoric acid etched undercut sidewalls," IEEE Photonics Technology Letters, vol. 21, no. 8, pp. 510-512, 2009.

[7] S. E. Brinkley, C. L. Keraly, J. Sonoda et al., "Chip shaping for light extraction enhancement of bulk c-plane light-emitting diodes," Applied Physics Express, vol. 5, no. 3, Article ID 032104, 3 pages, 2012.

[8] H. Y. Lee, X. Y. Huang, and C. T. Lee, "Light output enhancement of GaN-based roughened LEDs using bias-assisted photoelectrochemical etching method," Journal of the Electrochemical Society, vol. 155, no. 10, pp. H707-H709, 2008.

[9] C. C. Lin and C. T. Lee, "Enhanced light extraction of GaNbased light emitting diodes using nanorod arrays," Electrochemical and Solid-State Letters, vol. 13, no. 8, pp. H278-H280, 2010.

[10] D. H. Kim, C. O. Cho, Y. G. Roh et al., "Enhanced light extraction from GaN-based light-emitting diodes with holographically generated two-dimensional photonic crystal patterns," Applied Physics Letters, vol. 87, no. 20, Article ID 203508, 3 pages, 2005.

[11] H. K. Cho, J. Jang, J. H. Choi et al., "Light extraction enhancement from nanoimprinted photonic crystal GaN-based blue lightemitting diodes," Optics Express, vol. 14, no. 19, pp. 86548660, 2006.

[12] Y. C. Chang, J. K. Liou, and W. C. Liu, "Improved light extraction efficiency of a high-power GaN-Based light-emitting diode with a three-dimensional-photonic crystal (3-D-PhC) backside reflector," IEEE Electron Device Letters, vol. 34, no. 6, pp. 777-779, 2013.

[13] N. Lobo, H. Rodriguez, A. Knauer et al., "Enhancement of light extraction in ultraviolet light-emitting diodes using nanopixel contact design with Al reflector," Applied Physics Letters, vol. 96, no. 8, Article ID 081109, 3 pages, 2010.

[14] X. Yan, M. Shatalov, T. Saxena, and M. S. Shur, "Deep-ultraviolet tailored- and low-refractive index antireflection coatings for light-extraction enhancement of light-emitting diodes," Journal of Applied Physics, vol. 113, no. 16, Article ID 163105, 5 pages, 2013.

[15] C. T. Lee and C. Y. Chuang, "Light extraction enhancement of GaN-based flip-chip light-emitting diodes using diffused nanorod reflector," Applied Physics Express, vol. 5, no. 11, Article ID 112104, 3 pages, 2012.

[16] C. T. Lee and H. W. Kao, "Long-term thermal stability of Ti/Al/Pt/Au Ohmic contacts to n-type GaN," Applied Physics Letters, vol. 76, no. 17, pp. 2364-2366, 2000.

[17] C. S. Lee, Y. J. Lin, and C. T. Lee, "Investigation of oxidation mechanism for ohmic formation in $\mathrm{Ni} / \mathrm{Au}$ contacts to p-type GaN layers," Applied Physics Letters, vol. 79, no. 23, pp. 38153817, 2001. 

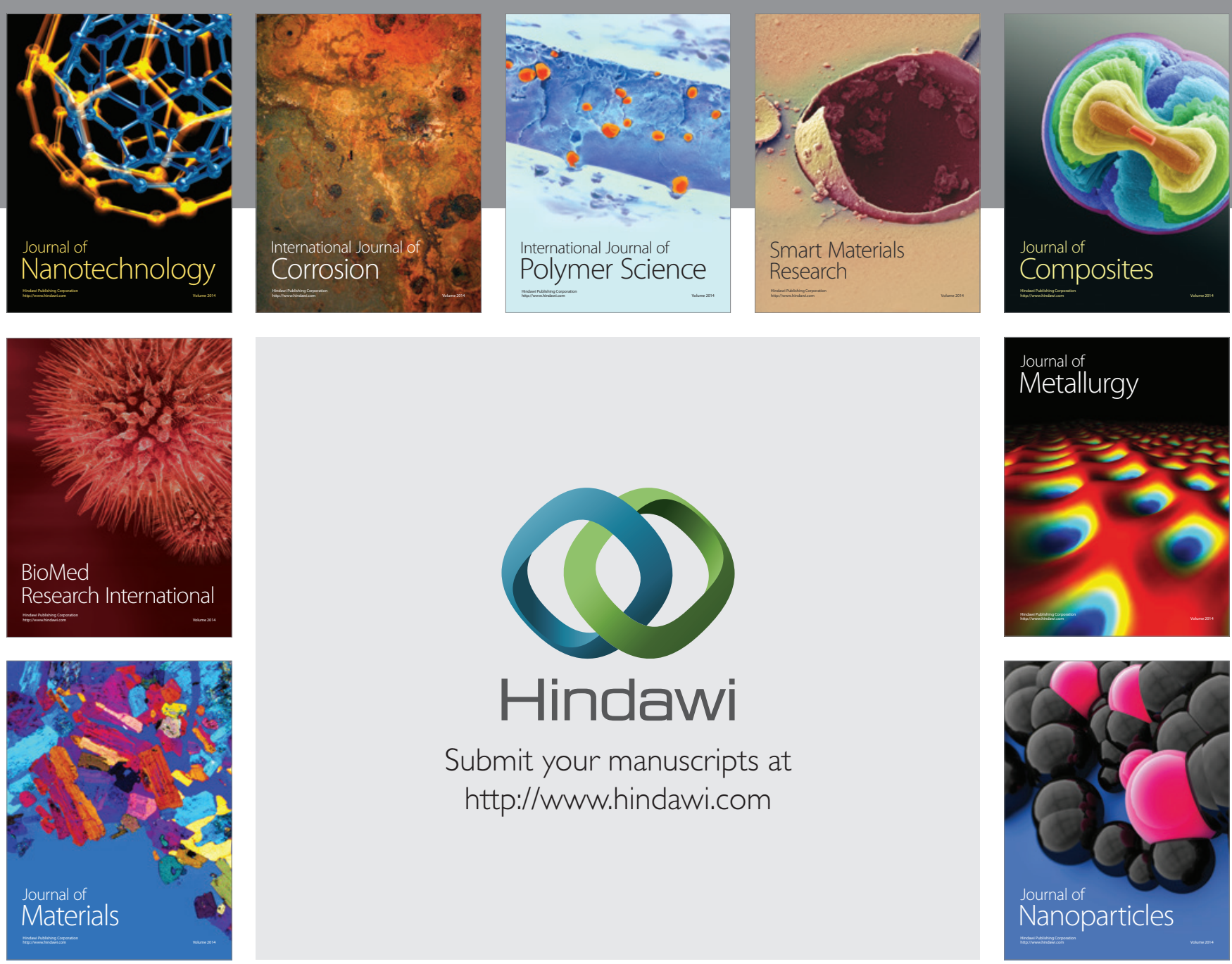

Submit your manuscripts at http://www.hindawi.com
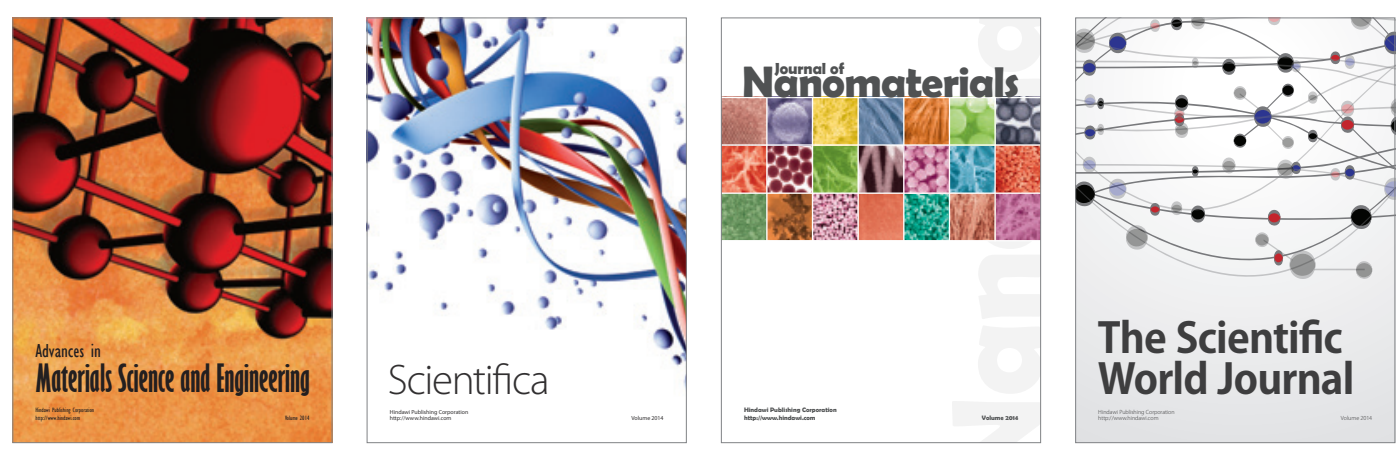

\section{The Scientific World Journal}
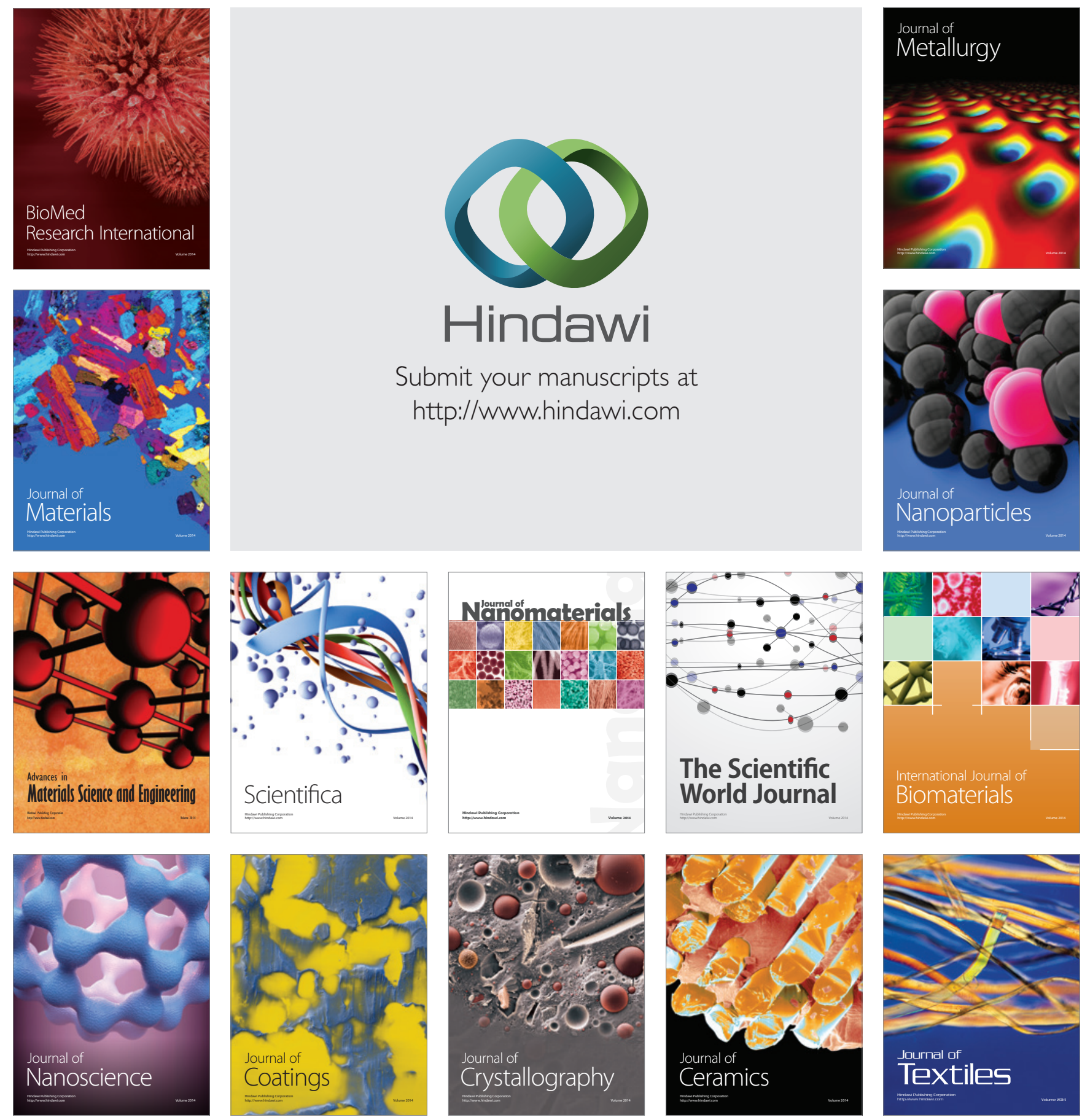